\title{
Determinants of Walking among Middle-Aged and Older Overweight and Obese Adults: Sociodemographic, Health, and Built Environmental Factors
}

\author{
Samuel N. Forjuoh, ${ }^{1,2}$ Marcia G. Ory, ${ }^{2}$ Jaewoong Won, ${ }^{3}$ Samuel D. Towne Jr., ${ }^{2}$ \\ Suojin Wang, ${ }^{4}$ and Chanam Lee ${ }^{3}$ \\ ${ }^{1}$ Department of Family \& Community Medicine, Baylor Scott \& White Health, College of Medicine, Texas A\&M Health Science Center, \\ Temple, TX, USA \\ ${ }^{2}$ Department of Health Promotion \& Community Health Sciences, School of Public Health, Texas A\&M University, \\ College Station, TX, USA \\ ${ }^{3}$ Department of Landscape Architecture \& Urban Planning, College of Architecture, Texas A\&M University, College Station, TX, USA \\ ${ }^{4}$ Department of Statistics, College of Science, Texas A\&M University, College Station, TX, USA
}

Correspondence should be addressed to Samuel N. Forjuoh; samuel.forjuoh@bswhealth.org

Received 15 March 2017; Accepted 31 May 2017; Published 4 July 2017

Academic Editor: Eliot Brinton

Copyright (C) 2017 Samuel N. Forjuoh et al. This is an open access article distributed under the Creative Commons Attribution License, which permits unrestricted use, distribution, and reproduction in any medium, provided the original work is properly cited.

Background. This study examined the association between selected sociodemographic, health, and built environmental factors and walking behaviors of middle-aged and older overweight/obese adults. Methods. Subjective data were obtained from surveys administered to community-dwelling overweight/obese adults aged $\geq 50$ years residing in four Texas cities from October 2013 to June 2014, along with objective data on neighborhood walkability (Walk Score ${ }^{\mathrm{TM}}$ ). Multivariate logistic regression identified factors predicting the odds of walking the recommended $\geq 150$ minutes per week for any purpose. Results. Of 253 participants, the majority were non-Hispanic white (81.8\%), married (74.5\%), and male (53.4\%) and reported an annual income of $\geq \$ 50,000$ (65.5\%). Approximately, half were employed $(49.6 \%)$ or had at least a college degree (51.6\%). Walking the recommended $\geq 150$ minutes per week for any purpose $(n=57,22.5 \%)$ was significantly associated with having at least a college degree $(\mathrm{OR}=5.55$, $95 \% \mathrm{CI}=1.79-17.25)$, having no difficulty walking a quarter of a mile $(\mathrm{OR}=5.18,95 \% \mathrm{CI}=1.30-20.83)$, and being unemployed $(\mathrm{OR}=3.25,95 \% \mathrm{CI}=1.18-8.93)$ as well as perceived presence of sidewalks/protected walkways $(\mathrm{OR}=3.56,95 \% \mathrm{CI}=1.10-11.50)$ and perceived absence of distracted drivers in the neighborhood $(\mathrm{OR}=4.08,95 \% \mathrm{CI}=1.47-11.36)$. Conclusion. Addressing neighborhood conditions related to distracted drivers and pedestrian infrastructure may promote walking among middle-aged and older overweight/obese individuals.

\section{Introduction}

The global public health burden of obesity is well established as is the influence of physical activity on the health and wellbeing of individuals who are overweight or obese $[1,2]$. In the United States, obesity is a major public health problem for all ages, but particularly for middle-aged and older adults who do not seem to engage in adequate physical activity. This is a timely issue given projections that those aged 65 years or older are expected to nearly double between 2012 and 2050 [3]. In fact, obesity is higher among middle-aged and older adults than among their younger counterparts [4]. Approximately two-thirds of the adult population in the United States is overweight and nearly one-third is obese $[4,5]$, yet most do not get adequate physical activity [6].

The federal 2008 Physical Activity Guidelines for Americans recommend adults to avoid inactivity and have at least 150 minutes of moderate-intensive aerobic activity weekly and muscle-strengthening activities on two or more days every week. For older adults who cannot do 150 minutes 
of moderate-intensive aerobic activity due to chronic conditions, the recommendation is for them to be physically active as their abilities and conditions allow [7]. However, most middle-aged and older adults do not meet this guideline. In 2014, the percentage of adults aged 45-54 years and 55-64 years who met the federal 2008 Physical Activity Guidelines for Americans for both aerobic activity and musclestrengthening exercise was $19.3 \%$ and $16.1 \%$, respectively, compared to $25.1 \%$ and $31.1 \%$ for those aged $25-44$ years and 18-24 years, respectively. The corresponding rates for those aged $65-74$ years and 75 years or older were $14.4 \%$ and $7.9 \%$, respectively [8]. Physical activity in old age is particularly important for disease prevention, health maintenance, quality of life, overall independence, and fall prevention [7, $9,10]$. Preventing or delaying chronic diseases is a salient issue as nearly nine in 10 older adults have at least one chronic condition, with nearly three in four having at least two chronic conditions [11]. Thus, identifying factors that may lessen the burden of chronic disease as individuals age is especially timely with this rapidly aging population [3].

Although there are numerous ways to be physically active, walking is one of the most popular and frequently recommended forms of physical activity, especially for middleaged and older adults who may have difficulty with certain forms of rigorous physical activity and in line with the current recommendation of $\geq 150$ minutes of exercise per week (as opposed to specifying 30 minutes of moderateintensity exercise five days per week) for older adults $[12,13]$. In fact, walking or jogging was rated the highest among older adults' favorite activities in a large nationally representative sample of older adults [14].

Walking is important for preventing obesity as well as promoting better health and reducing healthcare costs for those who are already obese $[15,16]$. Cognizant of the physical activity guidelines by the physicians in our setting [17], walking was cited as the most common activity recommended by family physicians for their obese patients, along with bicycling and swimming [18]. Regular physical activity such as walking can prevent or ameliorate the effects of many chronic conditions that afflict middle-aged and older adults, lower their quality of life, and contribute to the leading causes of death. Therefore, promoting walking as a form of physical activity in middle-aged and older adults can directly benefit them through improved quality of life and reduced burden of chronic conditions. This is especially true for middle-aged and older adults who are overweight or obese.

While prior studies have uncovered predictors of walking among older adults, including the barriers and motivators $[19,20]$, less is known about the predictors of walking among middle-aged and older adults who are overweight or obese. The predictors for the latter population could be different given the added morbidity or chronic medical condition to their aging condition. In an exploratory study, Lee et al. [21] addressed barriers and motivators to walking among overweight and obese adults, but the sample included all adults aged 18 years or older and the focus was on age variations in barriers or motivators with little mention of health predictors of walking among this population. They, however, concluded that overweight and obese adults may experience considerable modifiable environmental barriers to walking.

This study examined factors associated with the walking behaviors of middle-aged and older overweight and obese adults, focusing on the influence of selected sociodemographic, health, and built environmental factors. In line with the behavioral-environment health model [21], it is important to understand which multilevel factors are most correlated with reported walking as a form of physical activity. Additionally important is having both subjective and objective measures of the built environment.

\section{Methods}

2.1. Study Design, Setting, and Participants. A cross-sectional survey was conducted from October 2013 to June 2014 in a large university-affiliated, integrated multispecialty healthcare system associated with a 220,000-member Health Maintenance Organization in four central Texas cities (Temple, Killeen, College Station, and Bryan). These cities included peri-urban environments where urban and rural features coexist within cities, which can exhibit diverse neighborhood contexts with a range of street and development patterns from car-dependent to fairly walkable environments. The survey used a standardized, online, and paper questionnaire that included open-ended and multiple choice questions. Study participants were community-dwelling overweight or obese adults aged $\geq 50$ years residing in one of the four cities and seen by a family physician in a primary care clinic in the previous three years who reported some level of walking as a form of physical activity. Objective data were also collected using Walk Score to capture walkability (i.e., accessibility to destinations) of the survey respondent's residential neighborhood. The study protocol was reviewed and approved by the Institutional Review Boards of Baylor Scott \& White Health and the Texas A\&M University.

2.2. Recruitment Procedure and Data Collection. Details of the research methods, including the procedures for recruitment and data collection, have been published elsewhere $[19,22,23]$. In brief, participants were recruited via electronic medical records (EMRs) that were utilized to conduct initial patient screening by age and geographic residence. Primary care providers were then provided with a list generated from the EMRs to identify potentially eligible patients from a sampling list, from which 7,543 recruitment letters were sent out. The sample was restricted to those who (a) had no difficulty reading, writing, and speaking English; (b) were not terminally ill; and (c) did not live in a nursing home or assisted-living community. In order to ensure patients' capability of walking as a form of physical activity, screening questions on the ability to walk in their neighborhood without major difficulty or for a quarter of a mile (approximately 2-3 city blocks) or for about 5-10 minutes were included at the front of the survey instrument.

The link to the online survey was sent to participants who opted for the online version $(69.5 \%)$ via provided email addresses, while paper surveys were mailed to those who opted for the paper version $(30.5 \%)$ to their provided 
addresses. Designed to take approximately 20 minutes to complete, the survey included questions on sociodemographic, health, and built environmental factors potentially related to walking. Previously validated or tested instruments including the Behavioral Risk Factor Surveillance System developed by the Centers for Disease Control and Prevention [24], Starting-The-Conversation developed by the University of North Carolina Prevention Partners [25], the International Physical Activity Questionnaire [26], and the Neighborhood Environment Walkability Scale [27] informed the survey. Each participant was offered a $\$ 10$ gift card at the completion of the survey.

2.3. Study Measures. The primary study outcome measure was walking the recommended $\geq 150$ minutes per week for any purpose. This measure of walking behavior was obtained by combining two survey items that estimated walking days for any purpose in a typical week and walking minutes for any purpose in each day. The outcome variable was dichotomized into (a) walking $\geq 150$ minutes per week for any purpose (as a proxy for meeting the federal 2008 Physical Activity Guidelines for Americans) and (b) walking $<150$ minutes per week for any purpose (as a proxy for not meeting the guidelines for physical activity).

We used Walk Score as one of our predictor variables to measure walkability of each participant's residential environment [28-30]. Walk Score is calculated based on an accessibility-based measure to various walkable destinations from home, providing an objective and disaggregated estimate of walkability around each participant's residence. Walk Score can be used to categorize areas that are walkable (Walk Score $\geq 50$ ) versus those that are car-dependent (Walk Score < 50) [28]. Neighborhood perception, captured from the survey, was conceptualized with several questions related to the built environments that focused on (1) neighborhood safety from traffic, for example, "There is so much traffic along nearby streets that it makes it difficult or unpleasant to walk in my neighborhood"; (2) neighborhood safety from crime, for example, "My neighborhood streets are well lit at night"; (3) neighborhood safety from physical injury risks, for example, "There are many broken sidewalks in my neighborhood"; (4) behavioral factors in neighborhood safety, for example, "There are many distracted drivers in my neighborhood (e.g., on the cell phone while driving)"; (5) social aspects of the neighborhood, for example, "People in my neighborhood know each other"; and (6) attractiveness of the neighborhood, for example, "There are many attractive buildings, homes or gardens to see in my neighborhood."

Other predictor variables were also captured from the survey and included anthropometric (i.e., being overweight or obese), social interaction (e.g., someone to walk with, dog in household), and demographic characteristics (e.g., age, gender, education) as well as health (e.g., difficulty walking for a quarter of a mile and health condition) variables.

2.4. Statistical Analyses. Descriptive statistics were used to characterize participants' anthropometric and sociodemographic data as well as their health conditions, walking, and built environmental behaviors. Pearson chi-square tests

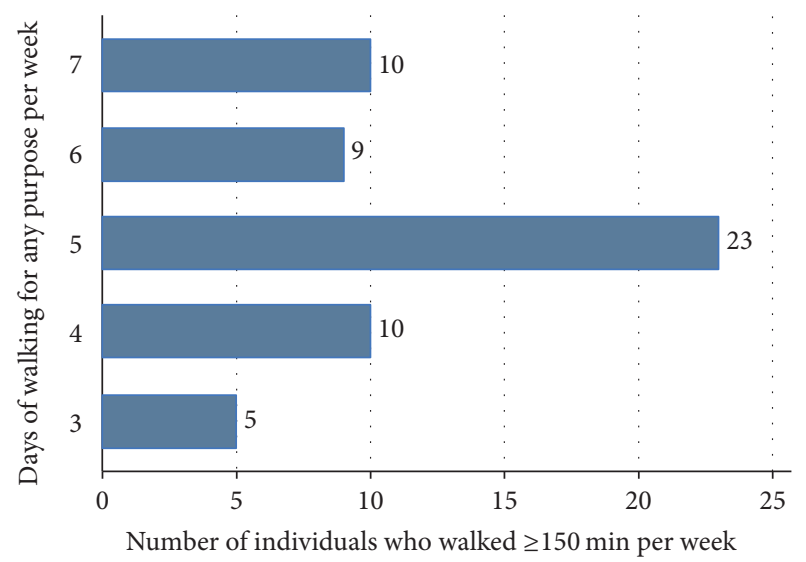

FIgURE 1: Number of days of walking for any purpose by middleaged and older overweight and obese individuals who walked $\geq 150$ minutes per week.

were then used to assess differences between participants who reported walking versus not walking the recommended $\geq 150$ minutes per week. Finally, multivariate logistic regression was used to predict walking the recommended $\geq 150$ minutes per week for any purpose using the selected sociodemographic, health, and built environmental factors. Those variables that showed statistical significance in the bivariate tests and were clinically sensible and plausible were added to the multivariate model. Adjusted odds ratios and 95\% confidence limits of the final multivariate model are reported. All analyses were conducted in 2016 using Stata 13 (StataCorp, College Station, TX). Statistical significance was set at the $P<0.05$ level.

\section{Results}

3.1. Survey Response and Walking Behaviors. Of the 496 patients who participated in the survey (adjusted response rate, 6.8\%), 102 participants were excluded for not meeting the study eligibility criteria (e.g., did not live in our study areas, lived in assisted facilities, and aged $<50$ years) or screening criteria (e.g., did not walk) or completing the survey. Of the remaining 394 participants, 141 were excluded for not being overweight or obese. Analyses for this study were therefore based on the remaining 253 participants who were overweight or obese adults, of whom 57 (22.5\%) reported walking the recommended $\geq 150$ minutes per week for any purpose.

Of the 57 who reported walking the recommended $\geq 150$ minutes per week for any purpose, most $(40.4 \%, n=23)$ reported walking 5 days per week, $17.5 \%(n=10)$ reported walking 7 days per week, and another $17.5 \%(n=10)$ reported walking 4 days per week, while $15.8 \%(n=9)$ reported walking 6 days per week and $8.8 \%(n=5)$ reported walking 3 days per week (Figure 1). The most popularly used places for walking were the neighborhood streets, green places with water features, and malls or shopping centers (Figure 2).

3.2. Anthropometric, Demographic, and Health Characteristics. Of the total sample who were overweight or obese adults 


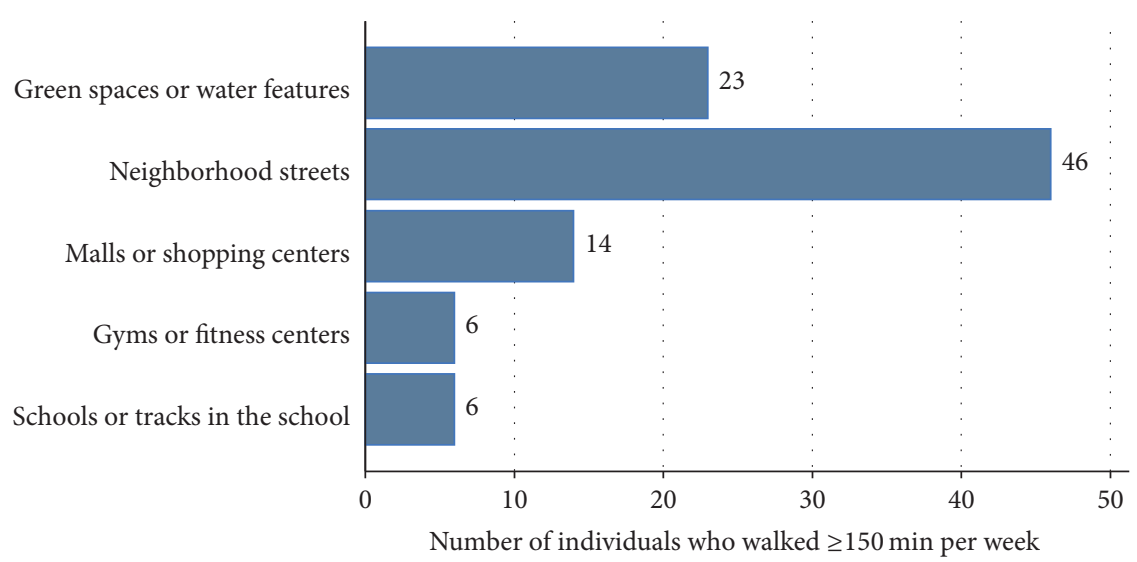

FIGURE 2: Places for walking for any purpose by middle-aged and older overweight and obese individuals who walked $\geq 150$ minutes per week.

$(n=253)$, the majority were overweight $(55.7 \%)$, non-Hispanic white $(81.8 \%)$, married $(74.5 \%)$, and male $(53.4 \%)$ and reported an annual household income of $\geq \$ 50,000(65.4 \%)$. Approximately, half were aged $\geq 65$ years $(48.2 \%)$, employed $(49.6 \%)$, or had at least a college degree $(51.6 \%)$. They were generally healthy, with $51.0 \%$ reporting very good to excellent health and $35.6 \%$ reporting good health. Overall, $23.8 \%$ reported having a little or some difficulty walking for a quarter of a mile. Nearly half of them reported receiving a primary care provider recommendation to be more physically active (Table 1).

\subsection{Social Support and Built Environmental Characteristics.} Table 2 summarizes the bivariate social support and built environmental characteristics of the overweight or obese participants. Few respondents reported having caregiving responsibilities for elders (15.1\%), while a substantial number reported having a dog in the household (41.9\%), and almost half of them reported having someone to walk with $(49.0 \%)$. The vast majority $(91.3 \%)$ resided in less walkable or cardependent areas (Walk Score $<50$ ) than walkable areas (Walk Score $\geq 50)$. The mean and median Walk Scores were 20.4 and 17.0, respectively, with a range from 0 to 72 . However, no significant differences were seen between those who walked the recommended $\geq 150$ minutes per week for any purpose and those who did not in terms of these social support variables.

Of the built environmental factors related to neighborhood safety from traffic, one showed a significant difference between those overweight or obese adults who walked the recommended $\geq 150$ minutes per week for any purpose and those who did not. Among those overweight or obese adults who walked the recommended $\geq 150$ minutes per week for any purpose, significantly more participants strongly agreed/agreed that there are crosswalks and pedestrian signals to help walkers cross busy streets in the neighborhood than those who strongly disagreed/disagreed (26.4\% versus $18.2 \%, P=0.01)$. Similarly, one variable among the built environmental factors related to neighborhood safety from physical injury risk showed a significant difference between the two groups. Significantly more overweight or obese participants strongly agreed/agreed that they were worried about falling when walking in the neighborhood than those who strongly disagreed/disagreed $(25.4 \%$ versus $11.4 \%, P=$ 0.045). None of the other built environmental variables related to neighborhood safety from crime and behavioral risk factors showed statistically significant differences.

3.4. Factors Associated with Walking the Recommended $\geq 150$ Minutes per Week for any Purpose among Overweight or Obese Adults in Multivariate Model. The strongest determinants of overweight or obese participants walking the recommended $\geq 150$ minutes per week for any purpose in a multivariate model (Table 3 ) were related to respondent's educational levels and favorable neighborhood perceptions. Compared to those with a high school diploma or some college, participants with a college degree or higher were more than five times as likely to walk the recommended $\geq 150$ minutes per week for any purpose $(\mathrm{OR}=5.55,95 \% \mathrm{CI}=1.79-17.25)$. Walking the recommended $\geq 150$ minutes per week for any purpose was significantly associated with participants who strongly disagreed/disagreed that there were many distracted drivers (e.g., on the cell phone while driving) in their neighborhood $(\mathrm{OR}=4.08,95 \% \mathrm{CI}=1.47-11.36)$ and those who strongly agreed/agreed that there are sidewalks or protected walkways (e.g., walking trails) in their neighborhood ( $\mathrm{OR}=3.56,95 \%$ $\mathrm{CI}=1.10-11.50$ ). Those employed were significantly less likely to walk the recommended $\geq 150$ minutes per week compared to those unemployed $(\mathrm{OR}=0.31,95 \% \mathrm{CI}=0.11-0.85)$ as were those who reported some difficulty walking for a quarter of a mile (OR $=0.19,95 \% \mathrm{CI}=0.05-0.77)$.

Nearly threefold more participants strongly disagreed/ disagreed that drivers do not yield to pedestrians or bicyclists in the neighborhood than those who strongly agreed/agreed, meaning that most felt that drivers do yield. The disagreement with "Drivers do not yield to pedestrians or bicyclists in my neighborhood" predicted a borderline association with extra walking $(P=0.087)$. As would be expected, there was a positive relationship between extra walking and having a dog in the household, although the trend was also only borderline in strength $(P=0.098)$. Being overweight or obese and health condition as well as other social interaction 
TABLE 1: Anthropometric, demographic, and health characteristics of study participants.

\begin{tabular}{|c|c|c|c|c|c|c|c|}
\hline \multirow[t]{2}{*}{ Variable } & \multicolumn{2}{|c|}{$\begin{array}{l}\text { Total participants } \\
\qquad(N=253)\end{array}$} & \multicolumn{2}{|c|}{$\begin{array}{l}\text { Walked } \geq 150 \text { min per } \\
\text { week for any purpose } \\
\qquad(n=57)\end{array}$} & \multicolumn{2}{|c|}{$\begin{array}{l}\text { Walked }<150 \text { min per } \\
\text { week for any purpose } \\
\qquad(n=196)\end{array}$} & \multirow[t]{2}{*}{$P$ value } \\
\hline & FREQ $^{a}$ & $\%$ & FREQ $^{\mathrm{a}}$ & $\%^{\mathrm{b}}$ & FREQ $^{\mathrm{a}}$ & $\%^{\mathrm{b}}$ & \\
\hline Weight status & & & & & & & 0.94 \\
\hline Overweight & 141 & 55.7 & 32 & 22.7 & 109 & 77.3 & \\
\hline Obese & 112 & 44.3 & 25 & 22.3 & 87 & 77.7 & \\
\hline Age group (years) & & & & & & & 0.65 \\
\hline $50-64$ & 131 & 51.8 & 28 & 21.4 & 103 & 78.6 & \\
\hline$\geq 65$ & 122 & 48.2 & 29 & 23.8 & 93 & 76.2 & \\
\hline Gender & & & & & & & 0.63 \\
\hline Male & 135 & 53.4 & 32 & 23.7 & 103 & 76.3 & \\
\hline Female & 118 & 46.6 & 25 & 21.2 & 93 & 78.8 & \\
\hline Race/ethnicity & & & & & & & 0.53 \\
\hline Other & 46 & 18.2 & 12 & 26.1 & 34 & 73.9 & \\
\hline Non-Hispanic white & 206 & 81.8 & 45 & 21.8 & 161 & 78.2 & \\
\hline Marital status & & & & & & & 0.22 \\
\hline Divorced/widowed & 64 & 25.5 & 11 & 17.2 & 53 & 82.8 & \\
\hline Married/living with a partner & 187 & 74.5 & 46 & 24.6 & 182 & 75.4 & \\
\hline Education & & & & & & & $0.012^{*}$ \\
\hline High school or some college & 118 & 48.4 & 18 & 15.2 & 100 & 84.8 & \\
\hline College graduate or graduate & 126 & 51.6 & 36 & 28.6 & 90 & 71.4 & \\
\hline Employment & & & & & & & 0.198 \\
\hline Not employed & 126 & 50.4 & 33 & 26.2 & 93 & 73.8 & \\
\hline Employed & 124 & 49.6 & 24 & 19.3 & 100 & 80.7 & \\
\hline Annual household income & & & & & & & 0.070 \\
\hline$<\$ 50,000$ & 85 & 34.6 & 14 & 16.5 & 71 & 83.5 & \\
\hline$\geq \$ 50,000$ & 161 & 65.4 & 43 & 26.7 & 118 & 73.3 & \\
\hline Difficulty walking for a quarter of a mile & & & & & & & $0.002^{* *}$ \\
\hline Not at all difficult & 192 & 76.2 & 52 & 27.1 & 140 & 72.9 & \\
\hline Only a little/somewhat & 60 & 23.8 & 5 & 8.3 & 55 & 91.7 & \\
\hline Health condition & & & & & & & 0.37 \\
\hline Poor to fair & 34 & 13.4 & 5 & 14.7 & 29 & 85.3 & \\
\hline Good & 90 & 35.6 & 19 & 21.1 & 71 & 78.9 & \\
\hline Very good to excellent & 129 & 51.0 & 33 & 25.6 & 96 & 74.4 & \\
\hline $\begin{array}{l}\text { Received PCP recommendation } \\
\text { to be more physically active }\end{array}$ & & & & & & & 0.177 \\
\hline No & 130 & 51.8 & 34 & 26.1 & 96 & 73.9 & \\
\hline Yes & 121 & 48.2 & 23 & 19.0 & 98 & 81.0 & \\
\hline
\end{tabular}

factors such as having someone to walk with and care-giver responsibilities for elders as well as Walk Score were not significantly associated with the odds of walking the recommended $\geq 150$ minutes per week for any purpose among overweight or obese adults.

Counter-intuitively, walking the recommended $\geq 150$ minutes per week for any purpose was significantly associated with participants who strongly agreed/agreed that most drivers exceeded the posted speed limits while driving, strongly disagreed/disagreed that walkers and bikers on the streets can be easily seen, and strongly agreed/agreed that there is so much traffic along nearby streets (Table 3 ).

\section{Discussion}

In this cross-sectional study of community-dwelling overweight and obese adults aged 50 years or older in central Texas, $22.5 \%$ reported walking the recommended $\geq 150$ 


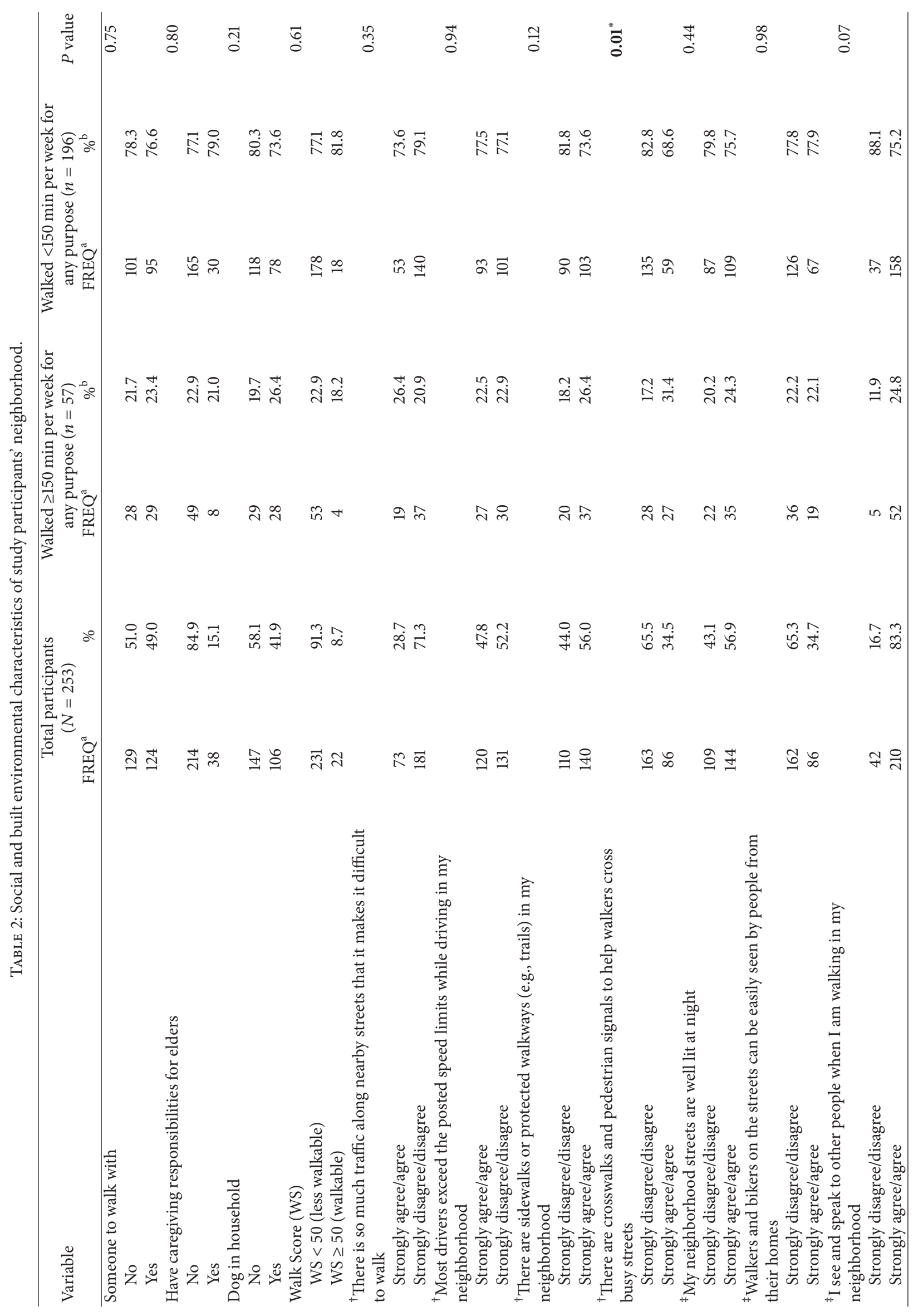




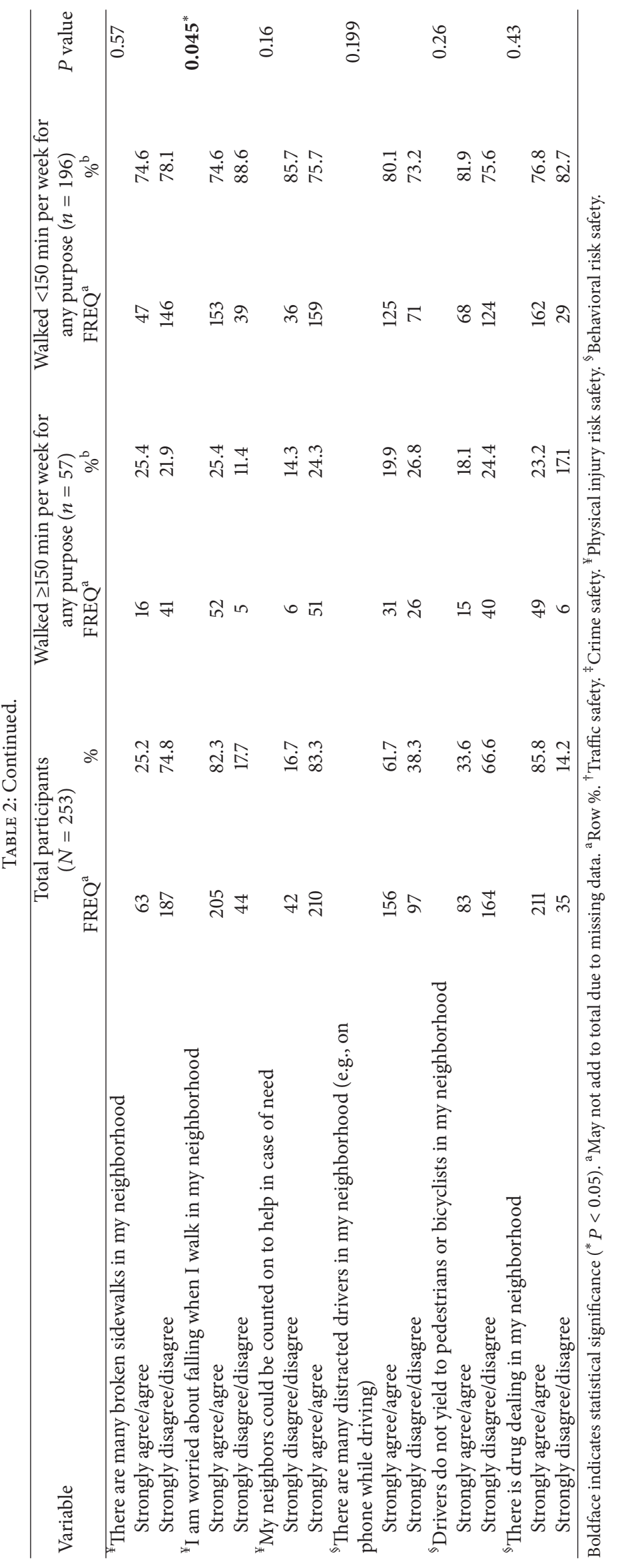


TABLE 3: Adjusted ORs and 95\% CI of walking the recommended $\geq 150$ minutes per week for any purpose.

\begin{tabular}{|c|c|c|c|}
\hline Variable & OR & 95\% CI & $P$ value \\
\hline \multicolumn{4}{|l|}{ Education } \\
\hline High school or some college & 1.00 & - & \\
\hline College graduate or graduate school & 5.55 & $1.79-17.25$ & $0.003^{* *}$ \\
\hline \multicolumn{4}{|l|}{ Difficulty walking for a quarter of a mile } \\
\hline Not at all difficult & 1.00 & - & \\
\hline Only a little or somewhat difficult & 0.19 & $0.05-0.77$ & $0.020^{*}$ \\
\hline \multicolumn{4}{|l|}{ There are many distracted drivers in the neighborhood } \\
\hline Strongly agree/agree & 1.00 & - & \\
\hline Strongly disagree/disagree & 4.08 & $1.47-11.36$ & $0.007^{* *}$ \\
\hline \multicolumn{4}{|c|}{ There are sidewalks or protected walkways in neighborhood } \\
\hline Strongly disagree/disagree & 1.00 & - & \\
\hline Strongly agree/agree & 3.56 & $1.10-11.50$ & $0.034^{*}$ \\
\hline \multicolumn{4}{|l|}{ Drivers do not yield to pedestrians or bicyclists } \\
\hline Strongly agree/agree & 1.00 & - & \\
\hline Strongly disagree/disagree & 2.67 & $0.87-8.22$ & 0.087 \\
\hline \multicolumn{4}{|c|}{${ }^{9}$ Most drivers exceed the posted speed limits while driving } \\
\hline Strongly disagree/disagree & 1.00 & & \\
\hline Strongly agree/agree & 2.85 & $1.10-7.41$ & $0.031^{*}$ \\
\hline \multicolumn{4}{|l|}{ 'Walkers and bikers on the streets can be easily seen } \\
\hline Strongly agree/agree & 1.00 & & \\
\hline Strongly disagree/disagree & 4.00 & $1.17-13.70$ & $0.027^{*}$ \\
\hline \multicolumn{4}{|l|}{ 'There is so much traffic along nearby streets } \\
\hline Strongly disagree/disagree & 1.00 & & \\
\hline Strongly agree/agree & 4.33 & $1.47-12.66$ & $0.008^{* *}$ \\
\hline \multicolumn{4}{|l|}{ Employment } \\
\hline Not employed & 1.00 & - & \\
\hline Employed & 0.31 & $0.11-0.85$ & $0.022^{*}$ \\
\hline \multicolumn{4}{|l|}{ Annual household income } \\
\hline$<\$ 50,000$ & 1.00 & - & \\
\hline$\geq \$ 50,000$ & 1.55 & $0.47-5.20$ & 0.474 \\
\hline \multicolumn{4}{|l|}{ Age group (years) } \\
\hline $50-64$ & 1.00 & - & \\
\hline$\geq 65$ & 0.87 & $0.30-2.51$ & 0.791 \\
\hline \multicolumn{4}{|l|}{ Race/ethnicity } \\
\hline Other & 1.00 & - & \\
\hline Non-Hispanic white & 0.35 & $0.10-1.21$ & 0.096 \\
\hline \multicolumn{4}{|l|}{ Marital status } \\
\hline Divorced, widowed, separated, or never married & 1.00 & - & \\
\hline Married or living with a partner & 0.73 & $0.20-2.63$ & 0.625 \\
\hline \multicolumn{4}{|l|}{ Gender } \\
\hline Male & 1.00 & - & \\
\hline Female & 0.78 & $0.30-2.06$ & 0.621 \\
\hline \multicolumn{4}{|l|}{ Weight status } \\
\hline Overweight & 1.00 & - & \\
\hline Obese & 1.30 & $0.52-3.26$ & 0.570 \\
\hline
\end{tabular}


TABLE 3: Continued.

\begin{tabular}{lcc}
\hline Variable & OR & 95\% CI \\
\hline Health condition & 1.00 & - \\
$\quad$ Poor to fair & 3.13 & $0.47-20.67$ \\
Good & 6.87 & $0.96-49.33$ \\
$\quad$ Very good to excellent & & - \\
Someone to walk with & 1.00 & $0.19-1.38$ \\
$\quad$ No & 0.51 & - \\
Yes & & 0.183 \\
Dog in household & 1.00 & $0.87-4.90$ \\
No & 2.07 & - \\
$\quad$ Yes & & 0.098 \\
Has caregiving responsibilities for elders & 1.00 & $0.17-2.33$ \\
No & 0.64 & - \\
$\quad$ Yes & & 0.495 \\
Walk Score & 1.00 & $0.40-7.27$ \\
Less walkable & 1.71 & 0.467 \\
Walkable &
\end{tabular}

$N=209$. Likelihood Ratio $\mathrm{Chi}^{2}=53.33(P=0.014)$. Pseudo $R^{2}=0.245$. Boldface indicates statistical significance $\left({ }^{*} P<0.05 ;{ }^{* *} P<0.01\right) .{ }^{9}$ Counter-intuitive association.

minutes per week for any purpose and three personal variables, including having at least a college degree, not having any difficulty walking for a quarter of a mile, and not being employed, were identified as significant personal level determinants of walking the recommended $\geq 150$ minutes per week for any purpose after controlling for other covariates. Unfortunately, no comparable state or national data on the percentage of overweight and obese adults in a comparable age group who walked $\geq 150$ minutes per week could be found.

From the neighborhood built environmental variables, strong disagreement with the perception that there are many distracted drivers (e.g., on the cell phone while driving) in one's neighborhood was found to be positively associated with walking the recommended $\geq 150$ minutes per week for any purpose. Further, strong agreement that there are sidewalks or protected walkways (e.g., trails) in one's neighborhood was found to be associated with the increased odd of walking $\geq 150$ minutes per week for any purpose. Thus, the relative importance of having sidewalks and protected walkways in one's neighborhood for walking can serve as a target for environmental interventions that focus on either maintaining or building such structures. It is also possible that those who walk more are more likely to know the pedestrian infrastructure in the neighborhood, such as sidewalks and walkways. Therefore, programs and campaigns to increase awareness of pedestrian infrastructure available in the neighborhood, as well as policies aimed to reduce distracted drivers, may also require further attention as components of future walking intervention programs. To the best of our knowledge, this is the first study to assess determinants of walking among a population of overweight and obese middle-aged and older adults. However, these factors are the same as found for older adults of all weight status, including normal weight [19].
Features in the built environment may be more favorable for certain segments of the population such as those who are more educated, less healthy, unemployed, or retired [31]. In the current study, walking the recommended $\geq 150$ minutes per week for any purpose was found to be associated with individuals with at least a college degree and those unemployed possibly including those who are retired. Higher education can enhance an individual's knowledge about health promotion, including the need for more physical activity such as walking $[32,33]$ even for those who may be overweight or obese as found in this study. Thus, those seeking to promote physical activity campaigns and other interventions can use the results of this study to set targets and to tailor marketing materials. Similarly, physicians seeking to encourage patients to be more active may also use this information to target and tailor encouragement for physical activity to particularly at-risk patients (e.g., those with lower educational levels). Also, being unemployed or retired may be associated with the needed time to engage in more physical activity such as walking [34].

Safety from traffic and behavioral risks such as that found in this study, along with safety from crime and injury risks, are among the foremost factors for promoting walking [35]. Exposure of middle-aged or older adults to increased risks of being hit by a distracted driver due to lack of sidewalks or protected walkways may deter them from walking. In fact, older adults bear disproportionately high rates of fatality from traffic crashes, accounting for $18 \%$ of all pedestrian deaths, although they account for only $13 \%$ of the total population [36]. Neighborhoods without distracted drivers and with ample safety features such as sidewalks or protected walkways will definitely promote walking even among middle-aged and older overweight and obese adults. 
Despite the fact that the majority of the participants in this study resided in less walkable areas, one in five reported walking the recommended $\geq 150$ minutes per week for any purpose. This finding is encouraging and may imply that enhancing the walkability of the neighborhood will make more individuals walk in their neighborhood. Prior studies have shown associations between higher neighborhood walkability and decreased prevalence of overweight and obesity, possibly via increased physical activity such as walking [37, 38].

Several seemingly counter-intuitive associations were found with walking the recommended $\geq 150$ minutes per week for any purpose. These included strong agreement that most drivers exceeded the posted speed limits while driving and that there was so much traffic along nearby streets making it difficult or unpleasant to walk in one's neighborhood as well as strong disagreement that walkers and bikers on the neighborhood streets can be easily seen by people from their homes and were rather unusual. However, these findings are likely due to the increased awareness of or sensitivity to those neighborhood conditions influencing pedestrians among those who walk more. For example, those who walk a lot (meeting the recommended $\geq 150$ minutes) are more likely to witness and consider inadequate driver behaviors, lack of visual surveillance, and heavy traffic to be problematic. The observation of so much traffic can be balanced with some observed positive, albeit insignificant, driver behavior of yielding to pedestrians or bicyclists. This observation may indicate that heavy traffic is associated with neighborhood walking, but safe driving behaviors should be encouraged. Although designing the roadway to reduce traffic is very important, driver behavior towards pedestrians may be more important for promoting neighborhood walking.

Our study had some limitations that must be taken into consideration in the interpretation of the findings. First, the limitation of our study to the selected four sites reduces the generalizability of the findings as was the exclusion of non-English speaking subjects which may have missed others, particularly Hispanics, who are a large subset with documented overweight and obesity problems. Second, our study had a very low response rate, further impacting the generalizability of study findings. However, this is typical of studies that depend on EMRs for subject recruitment [21,39], and the actual refusal rate once a patient was identified was rather very low $(0.15 \%, 11$ out of 7,543$)$. Further, our intent was to explore the associations between different correlates and walking behaviors in an understudied population rather than to conduct a larger more national epidemiological study. Third, the survey item for walking behavior we used was "how many days in a typical week do you walk in your neighborhood." We did not thoroughly define respondents' neighborhood boundary, and the definition might have been different across respondents. Finally, the cross-sectional design of the study precludes determination of causality.

\section{Conclusions}

In conclusion, we found that neighborhood perceptions and built environmental characteristics appear to be important determinants of the walking behaviors of middle-aged and older overweight and obese individuals as presented previously [40] and to be presented in an upcoming conference [41]. Enhancing the neighborhood environments, especially those related to pedestrian walkways, driver behaviors, visual surveillance, and traffic conditions, has the potential to promote walking among these individuals as well as the general population. Such enhancement may include providing walking trails and beautiful neighborhoods conducive for walking. However, these neighborhood environment enhancements ought to take cognizance of the needs of middle-aged and older individuals who may be overweight or obese.

\section{Disclosure}

This paper was presented, in part, at the 5th World Conference on Controversies \& Consensus in Diabetes, Obesity, and Hypertension, Istanbul, Turkey, Nov. 5-7, 2015.

\section{Conflicts of Interest}

None of the authors declare any competing financial interests.

\section{Acknowledgments}

The authors thank Vanessa Hoelscher for study coordination and Phyllis Davis for secretarial duties. The study was supported by Baylor Scott \& White Health Institutional Research Fund (no. 120803).

\section{References}

[1] Y. C. Wang, K. McPherson, T. Marsh, S. L. Gortmaker, and M. Brown, "Health and economic burden of the projected obesity trends in the USA and the UK," The Lancet, vol. 378, no. 9793, pp. 815-825, 2011.

[2] J. M. Jakicic, B. H. Marcus, K. I. Gallagher, M. Napolitano, and W. Lang, "Effect of exercise duration and intensity on weight loss in overweight, sedentary women: a randomized trial," Journal of the American Medical Association, vol. 290, no. 10, pp. 1323-1330, 2003.

[3] J. M. Ortman, V. A. Velkoff, and H. Hogan, An aging nation: the older population in the United States, US Census Bureau, Washington, DC, USA, 2014.

[4] C. L. Ogden, M. D. Carroll, B. K. Kit, and K. M. Flegal, "Prevalence of childhood and adult obesity in the United States, 2011-2012," The Journal of the American Medical Association, vol. 311, no. 8, pp. 806-814, 2014.

[5] K. M. Flegal, D. Carroll, B. K. Kit, and C. L. Ogden, "Prevalence of obesity and trends in the distribution of body mass index among US adults, 1999-2010," Journal of the American Medical Association, vol. 307, no. 5, pp. 491-497, 2012.

[6] Centers for Disease Control and Prevention, "One in five adults meet overall physical activity guidelines, 2016," http://www.cdc .gov/media/releases/2013/p0502-physical-activity.htm.

[7] U.S. Department of Health and Human Services, 2008 Physical Activity Guidelines for Americans, U.S. Department of Health and Human Services, Washington, DC, USA, 2008.

[8] National Center for Health Statistics, Health, United States, 2015: With Special Feature on Racial and Ethnic Health Disparities, Hyattsville, MD, USA, 2016. 
[9] W. Chodzko-Zajko, ACSM’s Exercise for Older Adults, Lippincott Williams \& Wilkins, 2013.

[10] B. Elsawy and K. E. Higgins, "Physical activity guidelines for older adults," American Family Physician, vol. 81, no. 1, pp. 5559, 2010.

[11] G. Anderson, Chronic Care: Making The Case for Ongoing Care, Robert Wood Johnson Foundation, Princeton, NJ, USA, 2010.

[12] K. E. Mobily, "Walking among older adults," World Leisure Journal, vol. 56, no. 2, pp. 130-140, 2014.

[13] "Exercise Recommendations for Older Adults, 2016," http:// www.todaysgeriatricmedicine.com/news/ex_092210_03.shtml.

[14] S. L. Szanton, R. K. Walker, L. Roberts et al., "Older adults' favorite activities are resoundingly active: findings from the NHATS study," Geriatric Nursing, vol. 36, no. 2, pp. 131-135, 2015.

[15] I.-M. Lee and D. M. Buchner, "The importance of walking to public health," Medicine and Science in Sports and Exercise, vol. 40, no. 7, pp. S512-S518, 2008.

[16] M. E. Nelson and S. C. Folta, "Further evidence for the benefits of walking," American Journal of Clinical Nutrition, vol. 89, no. 1, pp. 15-16, 2009.

[17] Y. Hong, M. G. Ory, C. Lee, S. Wang, J. Pulczinski, and S. N. Forjuoh, "Walking and neighborhood environments for obese and overweight patients: perspectives from family physicians," Family Medicine, vol. 44, no. 5, pp. 336-341, 2012.

[18] S. N. Forjuoh, C. Lee, S. Wang, Y. Hong, and M. G. Ory, "Family physicians? perception on environmental influences in promoting physical activity in their obese patients," Open Journal of Preventive Medicine, vol. 02, no. 04, pp. 423-428, 2012.

[19] M. G. Ory, S. D. Towne, J. Won, S. N. Forjuoh, and C. Lee, "Social and environmental predictors of walking among older adults," BMC Geriatrics, vol. 16, no. 1, article no. 155, 2016.

[20] J. Van Cauwenberg, P. Clarys, I. De Bourdeaudhuij et al., "Physical environmental factors related to walking and cycling in older adults: the Belgian aging studies," BMC Public Health, vol. 12, no. 1, article no. 142, 2012.

[21] C. Lee, M. G. Ory, J. Yoon, and S. N. Forjuoh, "Neighborhood walking among overweight and obese adults: age variations in barriers and motivators," Journal of Community Health, vol. 38, no. 1, pp. 12-22, 2013.

[22] S. D. Towne, J. Won, S. Lee et al., "Using walk score ${ }^{\mathrm{TM}}$ and neighborhood perceptions to assess walking among middleaged and older adults," Journal of Community Health, vol. 41, no. 5, pp. 977-988, 2016.

[23] S. N. Forjuoh, C. Lee, J. Won, S. D. Towne, S. Wang, and M. G. Ory, "Correlates of receiving a recommendation for more physical activity from a primary care provider," American Journal of Preventive Medicine, vol. 52, no. 2, pp. 207-214, 2016.

[24] Centers for Disease Control and Prevention, Behavioral Risk Factor Surveillance System survey data, Department of Health and Human Services, Centers for Disease Control and Prevention, Atlanta, Ga, 2009.

[25] A. E. Paxton, L. A. Strycker, D. J. Toobert, A. S. Ammerman, and R. E. Glasgow, "Starting the conversation: performance of a brief dietary assessment and intervention tool for health professionals," American Journal of Preventive Medicine, vol. 40, no. 1, pp. 67-71, 2011.

[26] The International Physical Activity Questionnaire, "Short Last 7 Days Self-Administered Format, 2002," http://www.ipaq.ki.se.

[27] E. Cerin, B. E. Saelens, J. F. Sallis, and L. D. Frank, "Neighborhood environment walkability scale: Validity and development of a short form," Medicine and Science in Sports and Exercise, vol. 38, no. 9, pp. 1682-1691, 2006.
[28] Walk Score ${ }^{\mathrm{TM}}$, "Walk score methodology, 2016," https://www .walkscore.com/methodology.shtml.

[29] D. T. Duncan, J. Aldstadt, J. Whalen, S. J. Melly, and S. L. Gortmaker, "Validation of Walk Score ${ }^{\circledR}$ for estimating neighborhood walkability: an analysis of four US metropolitan areas," International Journal of Environmental Research and Public Health, vol. 8, no. 11, pp. 4160-4179, 2011.

[30] L. J. Carr, S. I. Dunsiger, and B. H. Marcus, "Walk Score ${ }^{\mathrm{TM}}$ as a global estimate of neighborhood walkability," American Journal of Preventive Medicine, vol. 39, no. 5, pp. 460-463, 2010.

[31] A. Forsyth, R. C. Brownson, and K. Day, "The built environment, walking, and physical activity: is the environment more important to some people than others?" Transportation Research Part D: Transport and Environment, vol. 14, no. 1, pp. 42-49, 2009.

[32] A. K. Van Der Bij, M. G. H. Laurant, and M. Wensing, "Effectiveness of physical activity interventions for older adults-a review," American Journal of Preventive Medicine, vol. 22, no. 2 , pp. 120-133, 2002.

[33] C. L. Craig, R. C. Brownson, S. E. Cragg, and A. L. Dunn, "Exploring the effect of the environment on physical activity: a study examining walking to work," The American Journal of Preventive Medicine, vol. 23, no. 2, pp. 36-43, 2002.

[34] S. Chung, M. E. Domino, S. C. Stearns, and B. M. Popkin, "Retirement and physical activity: analyses by occupation and wealth," American Journal of Preventive Medicine, vol. 36, no. 5, pp. 422-428, 2009.

[35] J. Won, C. Lee, S. N. Forjuoh, and M. G. Ory, "Neighborhood safety factors associated with older adults' health-related outcomes: a systematic literature review," Social Science and Medicine, vol. 165, pp. 177-186, 2016.

[36] National Highway Traffic Safety Administration, Traffic Safety Facts 2009, Department of Transportation, Washington, DC, USA, 2009.

[37] M. Chiu, B. R. Shah, L. C. Maclagan, M.-R. Rezai, P. C. Austin, and J. V. Tu, "Walk score ${ }^{\circledR}$ and the prevalence of utilitarian walking and obesity among Ontario adults: a cross-sectional study," Health Reports, vol. 26, no. 7, pp. 3-10, 2015.

[38] M. I. Creatore, R. H. Glazier, and Moineddetal, "Association of neighborhood walkability with change in overweight, obesity, and diabetes," Journal of the American Medical Association, vol. 315, no. 20, pp. 2211-2220, 2016.

[39] J. Murphy, M. Schwerin, J. Eyerman, and J. Kennet, "Barriers to survey participation among older adults in the national survey on drug use and health: The importance of establishing trust," Survey Practice, vol. 1, no. 2, 2008.

[40] S. N. Forjuoh, M. G. Ory, J. W. Won, S. Towne, S. J. Wang, and C. Lee, "Socio-environmental correlates of walking among overweight and obese older adults in an integrated healthcare system," in Proceedings of the 5th World Conference on Controversies \& Consensus in Diabetes, Obesity, and Hypertension, Istanbul, Turkey, Nov 5-7, 2015.

[41] S. N. Forjuoh, M. G. Ory, J. W. Won, S. Towne, S. J. Wang, and C. Lee, "Determinants of walking among middle-aged and older overweight and obese adults: Demographic, health, and socioenvironmental factors," in Proceedings of the 19th International Conference on Obesity, Singapore, Singapore, Jul 4-5, 2017. 


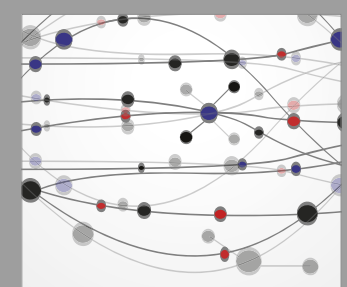

The Scientific World Journal
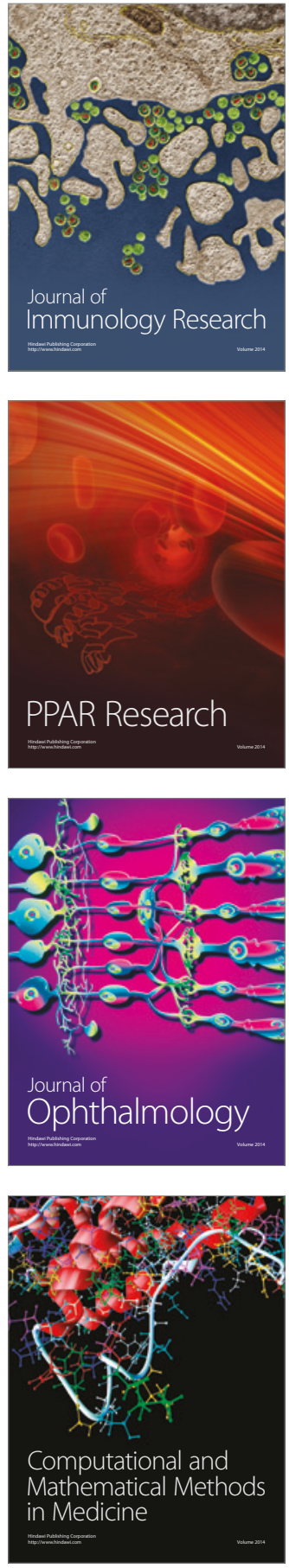

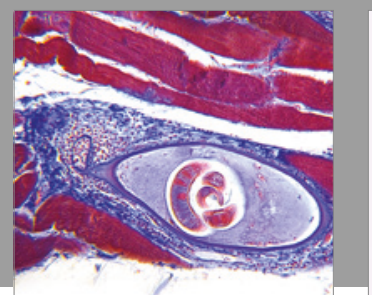

Gastroenterology Research and Practice
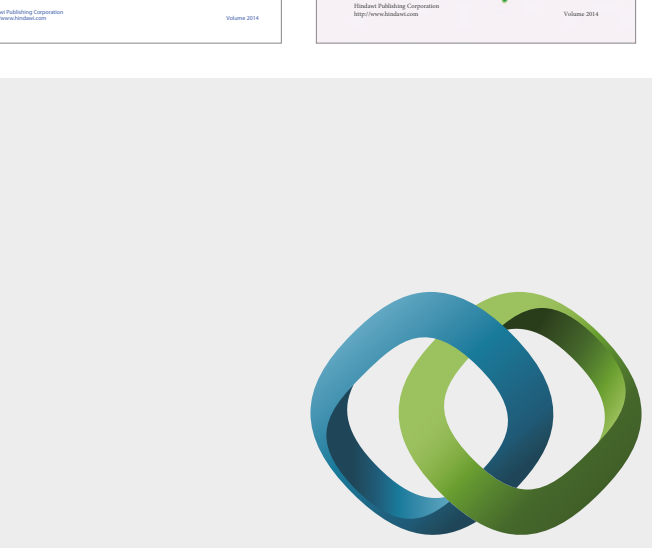

\section{Hindawi}

Submit your manuscripts at

https://www.hindawi.com
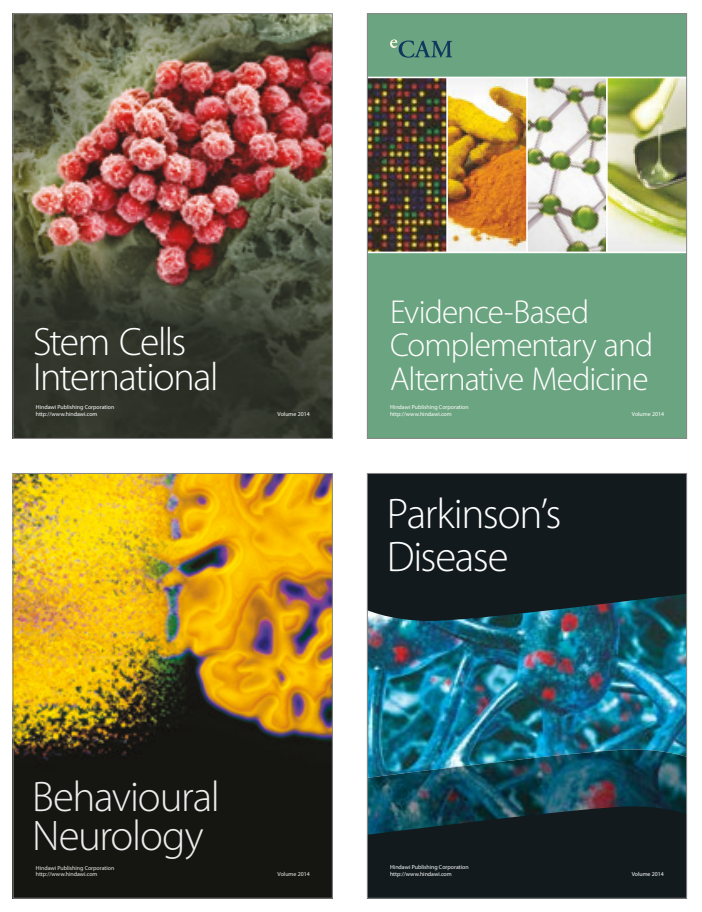
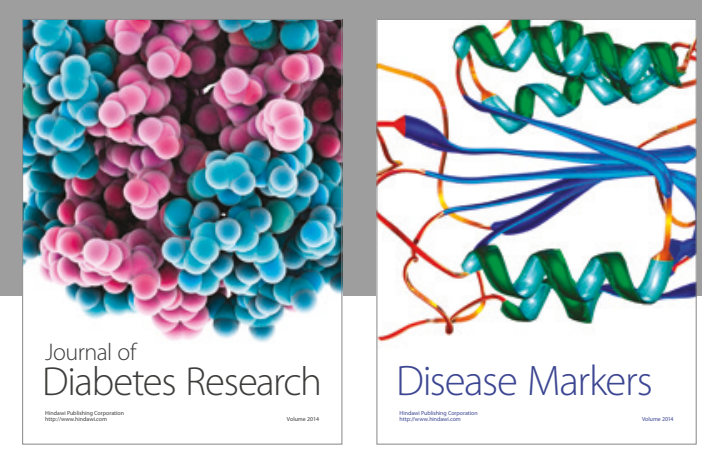

Disease Markers
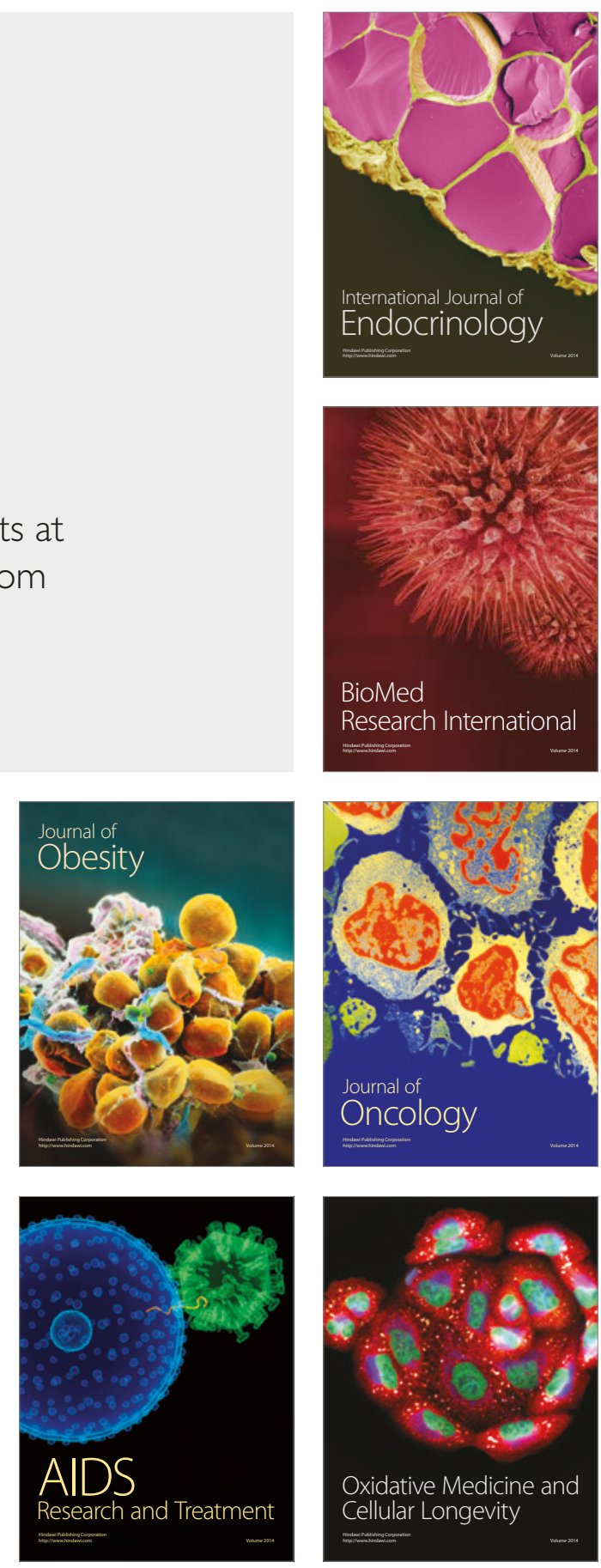